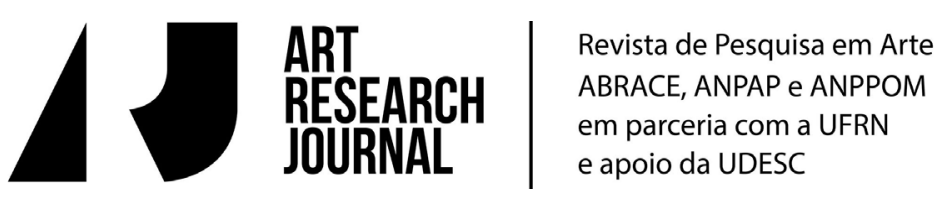

\section{O teatro atravessado}

Christophe Bident

Université de Picardie Jules Verne

O campo do teatro é infinito. Isso não é uma afirmação pretensiosa, uma forma de orgulho, de megalomania, de teosofia que faria do especialista em teatro o arauto de uma disciplina mais sublime que outras, o signatário de um pacto teórico com o diabo do qual Fausto poderia parecer o porta-voz. O campo do teatro não tem outros contornos que os da linguagem que Ihe dá uma potência de significação ilimitada. E esta potência é extremamente problemática. No âmbito das terras "ocidentais" e, particularmente, no acidente francês, "teatro" significa simultaneamente um espaço e um edifício da cidade, a cena ou mais especificamente o lugar cênico da representação, enfim, um gênero literário mais frequentemente qualificado como "dramático". Mas, a metáfora mais habitual, inteiramente lexicalizada, atribui à palavra "teatro" uma extensão e uma ressonância desmedidas. O "teatro das operações" é um lugar militar do combate bélico ou policial. Como a "comédia" ou o "cinema", o "teatro" qualifica a atitude ostensivamente mentirosa, exagerada, de má fé, que cada indivíduo pode adotar em uma relação intersubjetiva. Daí que, como naquilo que nós chamamos ainda hoje de "brincadeira de faz-de-conta", "teatro" possa designar não importa qual jogo infantil do policial e do ladrão, do médico e do paciente, etc. É, a cada vez, a potência duplamente ficcional e espetacular da palavra que é investida. E é precisamente esta potência que a linguagem filosófica ela mesma utiliza. Nos textos mais canônicos da antiguidade, como nos textos mais recentes da desconstrução, o uso da palavra "teatro" é raramente interrogado como tal. É antes do lado das ciências humanas, de uma sociologia como a de Erving Goffmann, que será elaborada uma "teoria da encenação da vida cotidiana". Durante a Segunda Guerra Mundial, escrevendo O ser e o nada, em um 
celebre café parisiense, Jean-Paul Sartre já havia usado a metáfora do "jogo" do garçom para elaborar uma teoria do comportamento. Tantas variantes, finalmente, do "grande teatro do mundo", em que se verifica um postulado metafísico que não encontrou ainda o operador de sua desconstrução.

Nós nos encontramos, assim, presos entre duas armadilhas: aquela da ordem que nos reduz à postulação de um pacto de adesão entre a cena como lugar fechado da ficção e a sala como comunidade efêmera de olhares convergentes, aquela que amplia o campo do teatro ao conjunto dos fatos sociais. Este vai e vem poderia provocar vertigem se ele não nos obrigasse a definir a cada vez, em cada lugar e a cada momento do mundo, o que entendemos por "teatro". Dito de outro modo: entre as representações do teatro elisabetano e a comédia espanhola do século de ouro nos pátios das hospedarias, as cerimônias rituais de tal grupo africano ou americano ou de tal comunidade balinesa, os balés reais nos jardins de Versailles, os espetáculos dadaístas nos cafés e nos cabarés, diferentes regimes de extraterritorialidade do teatro no teatro foram praticados. O que nos cabe definir desde já é em que sentido nós podemos falar hoje, ou pelos menos desde 1979 e do artigo de Rosalind Krauss sobre "a escultura em campo expandido", de teatro em campo expandido. Poderíamos, além do mais, discutir as implicações recíprocas desses dois enunciados, em uma arte como a de Tadeusz Kantor, por exemplo, onde a expansão do campo escultural encontra precisamente a expansão do campo teatral. Seria preciso também definir todas as condições que determinaram ou ao menos predispuseram o campo teatral pós-moderno a se expandir no contexto contemporâneo, que eu não hesitaria, da minha parte, de qualificar não de pós-dramático, mas de pós-moderno (1979: é também o ano de publicação do livro de Jean-François Lyotard, A condição pós-moderna). É um desafio enorme e necessário, que não cabe nos limites deste artigo. Podemos tentar, entretanto, nos aproximar dele, por meio de uma noção que eu chamaria de o teatro atravessado ${ }^{1}$.

Qual é esse teatro que nós podemos qualificar de "atravessado"? É a visão puramente abstrata de um espaço de representação em que intervêm corpos e linguagens. Por conseguinte, esse teatro pode ter lugar, concretamente, em teatros,

\footnotetext{
${ }^{1}$ Devo dizer aqui que esta noção, em processo de elaboração, foi "inventada" em comum acordo com José Da Costa, tradutor deste primeiro artigo que é dedicado a ele.
} 
mas também em museus, casas, galerias, porões, armazéns, fábricas desativadas ou não, hospitais, tendas, centros comerciais, praças públicas, ruas, em no man's lands, pedreiras, praias, rios, margens dos rios, barcos, ônibus, em estacionamentos, piscinas, banheiros, telas... A lista, evidentemente, não está encerrada. Ela confirma, se necessário for, o caráter ilimitado do campo da representação. Ela traduz a imensa fortuna que conheceu há várias décadas e que conhece ainda hoje o que nós pudemos nomear inadequadamente como a exteriorização do teatro, uma vez que o teatro é sempre-já exteriorizado, de onde se deduz ser preciso reconhecer que a extensão à qual ela remete foi, nesses tempos pós-modernos, intensamente utilizada.

Mas à medida da aceleração desenfreada das descobertas tecnológicas, em particular eletrônicas, o teatro foi também, em um tipo de movimento inverso, centrado de novo na proteção das suas salas, nas condições confortáveis que essas últimas, com uma arquitetura adaptada, com um equipamento sempre renovado, podem Ihe oferecer para tentar novas experiências laboratoriais. O teatro se encontrou assim atravessado, mais e mais, pelas outras artes (a mímica, a dança, o circo, a marionete, o vídeo, a escultura móvel ou industrial...), a ponto de criar categorias novas por concatenação (a dança-teatro, o teatro de objetos) ou por globalização (a performance) - e particularmente, há um quarto de século, pelo que nomeamos de novas tecnologias, sob a forma de intermidialidade, de transmidialidade, a fim de produzir, outro conceito novo, um "ator ampliado". Neste caso, é a cena que, literalmente falando, é atravessada por cabos, por fluxos, por drones, ondas, telas. Os processos eletrônicos, jogam com a recepção e particularmente com a percepção dos espectadores.

Haveria, assim, dois movimentos, um centrífugo, o outro centrípeto, de atravessamento do teatro: um mundo declarado teatro a partir do momento em que uma performance colocando em jogo corpos e linguagens é criada ali diante a atenção de espectadores declarados ou de simples passantes, um teatro declarado mundo a partir do momento em que uma tecnologia sofisticada permite representar virtualmente não importa que corpos e não importa que linguagens, em um regime que turva os paradigmas de realidade e de ficção. Mas, essa oposição é falsificadora. Ela é o resultado de conveniências científicas (é mais fácil experimentar novas tecnologias no interior de um espaço fechado e equipado), econômicas (é mais fácil fazer turnês em uma rede identificada de salas), políticas (é mais fácil entrar no campo de 
uma categoria que identifica o trabalho de uma companhia como sendo da ordem da rua ou do site-specific); ela não é nem confiável, nem durável. Suas determinações são infinitamente compreensíveis: elas preservam a autonomia e a economia da criação. Quer dizer, uma vez que, igualmente, é preciso pensá-las, o teatro atravessado é inseparável de suas condições de produção, de difusão e de representação.

Que têm em comum, além de sua contemporaneidade, esses dois movimentos aparentemente contrários? Concretamente, pode-se observar facilmente que as novas tecnologias podem também investir lugares exteriores e que os site-specific podem também, por sua vez, investir as salas escuras, pelo viés de uma importação de seus próprios materiais, de uma instalação de seu entorno ou ainda pela reprodução virtual de seu universo material e de suas condições espaço-temporais. Em um caso, como no outro, o teatro é atravessado por questões sociais e políticas, a geografia da arte, a política da escrita, os processos de decisão, os discursos dos espectadores... E é esta porosidade, este turvamento dos limites que funda a identidade dos dois movimentos percebidos.

Frederic Jameson atribui ao espaço pós-moderno duas qualidades: a homogeneidade e a fragmentariedade. Esta curiosa e paradoxal homogeneidade fragmentária caracteriza bastante bem o campo teatral "atravessado". O último meio século viu, pelo mundo afora, o teatro sair do teatro e desenvolver uma descrença necessária em relação ao edifício fechado com antigos palcos, à cena frontal e à sala escura. Esta descrença é completamente ligada àquilo que Jean-François Lyotard, para definir a idiossincrasia pós-moderna, chama de descrença frente às meta-narrativas. Porque a constituição da quarta parede, na virada do século $X X$, tinha tudo a ver com uma vontade didática, pedagógica e moral: Stanislavski, por exemplo, fala de "reeducar" o público (Stanislavski, 1997, p.43). Em seu caso, isso passa por um novo repertório, por uma concepção artística determinada do espaço, da iluminação e dos efeitos sonoros e, sobretudo, por uma elevação da atuação do intérprete ao nível dos personagens densos e sublimes da literatura, elevação essa que repousa sobre um método no qual a "crença" do ator no papel tem um lugar fundamental. A vontade de encantar o espectador repousa então sobre dois outros fundamentos: a crença idealista em uma transmissão quase mecânica da mensagem artística (eu experimento, então eu transmito; eu transmito, então eu sou; eu falo e a mensagem é ouvida); a assunção dos espectadores como um só (o 
público é uma massa singular; ele escuta, então ele é; ele se cultiva, então ele se eleva moralmente). Para Stanislavski, contemporâneo da abolição da escravatura e próximo aos meios revolucionários, o "teatro de arte" visa a uma emancipação propriamente moderna do público. Desse ponto de vista, pode-se dizer que a fragmentação brechtiana do tempo e do espaço teatral (interrupções diversas da ação dramática, supressão da quarta parede, diversificação e disseminação dos suportes da representação) aponta para uma pré-pós-modenidade: porque se Brecht acredita ainda na meta-narrativa marxista e em sua efetividade, a essência de seu gesto artístico repousa sobre um pensamento da transmissão que passa por uma exposição, uma explicação e um distanciamento (um estranhamento) dos signos da representação. Mas é evidentemente com a performance que a descrença pósmoderna se radicaliza. Em sua ponta mais extrema, na pureza de sua lógica, a performance interrompe o tempo comum e atravessa o espaço público de uma maneira inesperada. Ela é irredutível à ideia da repetição como à da representação. Para retomar as formulações de Jacques Rancière, ela partilha o sensível: ela propõe uma divisão e uma nova distribuição desse sensível, sem as quais nenhum espectador poderia se apropriar de sua mensagem. Claramente, ela visa a novos modos de subjetivação.

Quando, após várias experiências de teatro in situ (Igreja, hospital, presídio), ele procura acentuar sua reflexão sobre a história do Brasil, o Teatro da Vertigem decide atravessar o Brasil profundo². Essa viagem leva os membros da companhia de Brasilândia, bairro da periferia da principal metrópole do país, São Paulo, a Brasília, capital inaugurada em 1960, em meio ao nada, e à Brasiléia, pequena cidade de interior, situada ainda mais à oeste, na fronteira com a Bolívia. A viagem tem por objetivo levantar os materiais, encontrar os habitantes, desenvolver oficinas práticas com eles. Bernardo Carvalho, o dramaturgo, elabora passo a passo o roteiro do futuro espetáculo, $B R 3$, sobre o qual os atores vão improvisar. De volta a São Paulo, sede da companhia, é tomada a decisão de fazer o espetáculo no Rio Tietê. Correndo por zonas degradadas da capital, ladeado de parte a parte por avenidas com grande número de pistas, vítima de uma poluição desmesurada,

\footnotetext{
2 Este parágrafo deve muito às pesquisas de Guillaume Pinçon e a sua tese ainda inédita, Antropophagie du dehors: étude de théâtralités contemporaines au Brésil [Antropofagia do fora: estudo de teatralidades contemporâneas no Brasil] (Pinçon, 2013).
} 
o rio acolhe os espectadores em um barco e o espetáculo ocorre tanto dentro do barco, quanto às margens do Tietê. O desenvolvimento do percurso fluvial embasa a linha do relato. Para Antônio Araújo, diretor da companhia, escolher o Rio Tietê é "afogar na doença". Ele o exprime assim em uma entrevista de 2005:

Mais do que ressignificar o rio como espaço teatral, para mim tem a importância de ressensibilização do rio para o espectador. Esse rio que é um rio-esgoto. É olhar para a merda, é ver a merda, e uma merda que é também a nossa identidade. Por mais que a gente queira o projeto modernista como identidade - eu não estou dizendo que não seja, tem uma megalomania ali que é nossa identidade -, mas a merda também é nossa identidade. Acho que o rio traz isso (Audio e Fernandes, 2006, p. 25). ${ }^{3}$

Antônio Araújo evoca aqui uma situação simultaneamente concreta e abstrata. Os odores insuportáveis devidos à poluição do rio (fluidos industriais, dejetos diversos, cadáveres de animais...) deixam os espectadores indispostos, chegando, por vezes, quase a desmaiar. As cenas que têm lugar sucessivamente no cais, dentro do barco ou às margens do rio permitem seguir a saga de uma família remontando aos anos 1960, de Brasília a Brasilândia e à Brasileia: pelo espectro de um relato de família, tais cenas se atêm a um momento fundador da história recente do país, baseado em uma ideologia paradoxal, em seu duplo movimento, isto é, construtora e devastadora. É o modo pelo qual o espetáculo mostra a visão modernista do país: assegurar "cinquenta anos de progresso em cinco anos", segundo proclamara o Presidente Kubitschek, ao preço de condições de trabalho deploráveis e de assassinatos de operários; concretizar o lema moderno da nação, tomado de empréstimo ao positivismo comtiano, mas ao preço de um desenvolvimento e de uma concentração de favelas onde sobrevivem, não importa se bem ou se mal, os abandonados da "ordem e progresso". Então, o que os espectadores de $B R 3$ atravessam, é simultaneamente um rio poluído, uma metáfora do lixo, uma metonímia do dejeto, um contra produto da ideologia modernista. A "requalificação do rio em espaço teatral" (Antônio Araújo) realiza, com isso, um teatro atravessado por sua própria história, pela história do país, por uma constituição dessa história como ficção. Os espectadores são convidados a perceber um lugar

\footnotetext{
3 Entrevista realizada em 9 de outubro de 2005.
} 
que não é nunca percebido como tal e a se interrogar sobre a sua historicidade e a deles próprios. O teatro que o rio se torna é atravessado por esses atos, essas performances, essas construções notadamente orgânicas (atores, textos, corpos, gritos, vozes), cenográficas (cenas nas margens, estruturas construídas, andaimes) e sonoras (difusão de gravações, uso de microfones, sonorizações). Há ali uma "partilha do sensível", uma requalificação e uma redistribuição do perceptível, uma reinvenção do concebível, uma interrogação da história que lançam uma perturbação permanente sobre as categorias da realidade e da ficção, do fato bruto e do ensaio reflexivo, do passado e do presente. Os espectadores são convidados e mesmo intimados (porque há uma força de arrebatamento, levando-os de ônibus para um lugar inesperado, recebendo-os nesse lugar ao descerem do ônibus, em meio a sons de tiros, fazendo-os entrar em um barco apresentado como um antigo cinema transformado em igreja, embarcando-os em um percurso do qual eles não podem escapar, diferentemente de uma sala de espetáculos) a se interrogarem sobre a apropriação de sua história, segundo formas e modos diferenciados para cada indivíduo. Com efeito, segundo uma multiplicidade de critérios como a classe social, a origem urbana ou nacional, a vida cotidiana própria de cada um, cada espectador apreende esta história de uma maneira diferente. O que pensará, por exemplo, um espectador paulista da representação em São Paulo? O que pensará um espectador carioca da representação no Rio de Janeiro, onde o espetáculo foi transportado, transformado, verificado, dessa vez, não sobre um rio, mas em uma zona portuária da baia da Guanabara? Que pensará um espectador estrangeiro que estivesse passando por ali? É com uma grande intensidade material que o teatro atravessado se dirige a nossos modos e nossas formas de subjetivação.

Recompor a história, redistribuir o sensível. É a um tal empreendimento que se dedica, de maneira reiterada e cíclica, há uma década, o grupo Berlin. O grupo é composto por dois criadores videastas da cidade de Anvers (Bélgica), Bart Baele e Yves Degryse (três originalmente, com Caroline Rochlitz), que concebem a apresentação de seu trabalho sob uma forma teatral. Em Tagfish (2011), ${ }^{4}$ por exemplo, os espectadores entram em uma sala de teatro (ambiente escuro, dispositivo

\footnotetext{
${ }^{4}$ TAGFISH [Tous les grands changements commencent à la table], Todas as grandes mudanças começam à mesa. Festival de outono em Paris, 2011. O título refere a um termo do jogo de pôquer. Um tagfish é um jogador constate e safo, que não corre riscos, cujo jogo acaba se tornandomprevisível, ele mesmo uma presa fácil para os outros jogradores.
} 
frontal) e se encontram diante de a uma mesa oval instalada longitudinalmente na cena. Ao longo da curva oval, sete cadeiras fazem face aos espectadores. Elas esperam os convidados de uma conferência que não chegarão nunca, a não ser de modo virtual: aos encostos das cadeiras há telas alongadas que os recebem. Assim, a conferência se desenrola seguindo a edição de entrevistas realizadas. Tratase de debater um projeto de reconversão de um local pós-industrial desativado, da Renânia (região das proximidades do Rio Reno, na Alemanha), em uma cidade nova com habitações, escolas, hotéis de luxo, parques para recreação infantil... Os protagonistas do projeto foram entrevistados por Bart Baele e Yves Degryse. Suas intervenções são alternadas com imagens filmadas do lugar. Trata-se, então, de uma forma de vídeo-teatro documentário. Os espectadores não se deslocam no ambiente. É o ambiente que vem até eles e que monopoliza a cena por meio das telas. $O$ teatro é simultaneamente atravessado pelas imagens da localidade e pelas questões sociais, políticas e econômicas que o horizonte do dispositivo coloca em jogo. Este dispositivo literalmente produz e reproduz o real. Ele recorta as imagens da realidade natural e urbana, as imagens dos corpos e das roupas, as imagens das linguagens para organizá-las e distribuí-las aos espectadores. No mais puro dos postulados fenomenológicos, o trabalho sobre a percepção engaja um trabalho sobre a concepção: ele demanda uma elaboração ou uma reelaboração das maneiras de compreender. Em doze anos, a companhia criou nove espetáculos. Três deles se inserem em um ciclo intitulado Horror Vaccui; os seis outros, retratos de cidades, em um ciclo nomeado Holoceen. Vários dos retratos não são fornecidos em teatros. Aquele consagrado a Moscou, por exemplo, tem lugar sob uma espécie de tenda vermelha, uma estrutura itinerante que pode se instalar na praça pública; aquele dedicado a Iqaluit, pequena capital do território do noroeste canadense, é difundido sob uma cúpula metálica fina e com aberturas, que pode ser montada em um museu, uma galeria, ou não importa qual espaço interior suscetível de recebê-la. Nesses dois espetáculos, as telas são colocadas em locais e em alturas totalmente diferentes, ainda que, diferentemente do que ocorre em Tagfish, nenhum espectador possa ver todas as telas ao mesmo tempo, exceto se sofre de um forte estrabismo divergente e se tem olhos atrás da cabeça. Assim, potencialmente, na estética do grupo Berlin, há, então, não somente um trabalho sobre a filmagem, a montagem, o recorte e a recomposição da realidade, mas também uma fragmentação do visível: um dispositivo visual anti-totalitário que caracteriza 
bastante bem esta homogeneidade fragmentária atribuída por Jameson ao espaço pós-moderno. É, como tal, o teatro que se torna este espaço, turvando os limites entre realidade e ficção, perturbando os modos de percepção, propondo novos modos de conceber o real. $\mathrm{O}$ atravessamento do teatro pelo dispositivo tecnológico produz uma alteração de nossas representações deste real que nos é comum, que nos circunda, que nós pisamos e que nós respiramos ao sair do espetáculo. Ele se dirige a nossas políticas de subjetivação. Nós somos nós mesmos, cada um entre nós, que nos formulemos ou não isso, que sejamos ou não atores desse fato, atravessados pelos desafios sociológicos, econômicos, antropológicos dessas políticas. E o painel que Berlin nos propõe, que se expande junto a uma cidade a cada ano, nos convida igualmente a esta reelaboração subjetiva, pela escolha das cidades e das histórias que elas contêm. Passamos assim, para dizer rapidamente, de Jerusalém, materialmente atravessada pela divisão israelense-palestina, a Zvisdal, pequena cidade ucraniana próxima de Tchermobyl onde não subsiste mais que um velho casal que se negou a fugir, devastação "colateral" do mito de modernização soviética (e mais amplamente globalizada), ou de Moscou, capital de um BRICS submisso aos poderes obscuros do despotismo e da máfia, a Bonanza, antiga cidade mineradora do Colorado (Estados Unidos), onde subsistem sete habitantes que se detestam, versão documentada de Dogville de Lars Von Trier.

Eu gostaria de abordar o caso do dispositivo mais complexo que o grupo Berlin montou até aqui, no espetáculo intitulado Land's End. O assunto é um simples fait divers, de traço tragicômico, o assassinato de um belga conhecido pelo nome de "rei da panqueca", encomendado por sua esposa e efetuado por um francês que vive do outro lado da fronteira. A fronteira vai ser precisamente a questão do confronto entre as testemunhas. Este se dá em uma fazenda curiosamente atravessada pela própria fronteira, já que uma parte do edifício se encontra na Bélgica e a outra na França, certos cômodos estando eles mesmos divididos entre os dois países. Para evocar este fait divers e nos fazer apreender todas as suas complexidades psicológicas, jurídicas e políticas, Bart Baele e Yves degryse concebem um espetáculo que pode se dar em não importa qual lugar fechado, "teatro" propriamente dito ou não, que começa por uma caminhada em diversas instalações e prossegue com uma projeção de vídeo durante a qual momentos de "teatro" interferem, com um texto 
dramático e atores em carne e osso ${ }^{5}$. Os espectadores entram primeiro em uma grande sala onde são expostos a diversos objetos: um carro desmontado, algumas cabines equipadas com fones de ouvidos, uma estrutura de engrenagens mecânicas... Eles atravessam uma outra sala pequena na qual outros objetos e algumas telas estão dispostos antes de se depararem, passando pelas coxias, com o palco do teatro, onde encontram os últimos objetos, um lavatório coletivo, uma grande mesa, um conjunto de telas e de arquibancadas nas quais eles são convidados a se sentarem. Todos os ambientes vistos ao longo dessa caminhada que dura em torno de vinte minutos, e que pode, em seu conjunto, parecer inicialmente gratuita, representam os elementos do quebra-cabeça próprio à intriga criminal que vai ser representada e explicada aos espectadores na segunda parte da performance, o "espetáculo" propriamente dito. Quando nas arquibancadas, os espectadores estão diante de doze telas. Oito formam um sólido de quadro lados e de altura semelhante à dimensão humana, cada painel sendo composto de duas telas verticais de aproximadamente trinta centímetros por um metro colocadas uma na parte superior da outra. Alinhadas diante de nós, elas formam como que um muro ou um telão de fundo. Quatro outras telas, à alguma distância do vasto conjunto central, levemente em recuo, foram instaladas lateralmente: duas à esquerda, duas à direita, aqui, ainda, uma tela colocada na parte de cima da outra. Elas permitem criar uma espécie de contraponto, e mesmo jogar com o limite do fora-de-campo. As imagens projetadas fazem com que diferentes protagonistas do caso intervenham, interrogados alguns anos depois dos fatos. Eles aparecem frequentemente descalços em cada painel do sólido de quatro lados, acontecendo ainda de se responderem entre si, como ocorre na conferência de Tagfish. Assistimos também a uma reportagem sobre essa fazenda curiosamente situada em cima da fronteira. Mas, repentinamente, o dispositivo se torna mais complexo. Dois atores, que já apareceram nas telas, entram realmente "em cena": é a primeira, no trabalho do grupo Berlin, que aparece esse tipo de jogo, no qual a cena, mesmo sendo cena, torna-se ela própria estranha enquanto tal, ainda que estejamos no teatro, ou ao menos, em um dispositivo teatral. Nas telas e em cena, os atores interpretam su-

\footnotetext{
${ }^{5}$ Da minha parte, eu vi esse espetáculo na Maison de la Culture (Casa da Cultura), de Amiens (França). É a maneira pela qual essa caminhada foi organizada em três salas desse espaço que eu descrevo aqui. Ela pode ser apresentada diferentemente em outros locais, mas com os mesmos elementos e a mesma temporalidade.
} 
cessivamente dois textos: uma reconstituição de entrevistas entre o assassino de aluguel e a autora da encomenda (para essa montagem, Bart Baele e Yves Degryse não tiveram acesso aos processos da confrontação) e extratos de uma "peça de teatro", Dans la solitude des champs de coton (Na solidão dos campos de algodão) de Bernard-Marie Koltés. Encenada pela primeira vez em 1987 por Patrice Chéreau e rapidamente elevada à posição de clássico contemporâneo, a peça de Koltés coloca em cena um vendedor (dealer) e um cliente, sem que nós conheçamos jamais o objeto do negócio, ainda que numerosas interpretações tenham podido ser feitas, que vai da droga até a metáfora do desejo. O diálogo é construído à base de extensos monólogos cruzados. As frases frequentemente longas e complexas mais refletem a situação do que a tornam explícita, elas não a transformam, verdadeiramente, em uma narrativa. Utilizadas em relação às imagens do fait divers, elas criam uma clara discrepância, uma espécie de distanciamento do acontecimento pela ficção. Estamos, então, em um teatro atravessado pela instalação visual e o vídeo, os testemunhos judiciais, uma ficção de entrevista e um texto literário. Estamos em um teatro que realiza a passagem de um corpo de uma tela à outra e de uma tela ao palco, a passagem do verbo de uma fala de especialista a uma fala de escritor. Estamos colocados na situação de conhecer um fait divers, de abstrair as motivações do mesmo, de compreender as incompatibilidades das regras jurídicas de dois países vizinhos membros da União Europeia, que obrigam a esta confrontação absurda e grotesca dentro de um lugar simultaneamente único e dividido, uma fazenda com dois endereços atravessada por uma fronteira. No mesmo gesto, o espetáculo dá uma lição didática e provoca um vazio surpreendente, dissemina objetos e reconstitui fatos, trabalha sobre uma matéria tomada de empréstimo à realidade e abre um espaço metafórico, mistura diversas ordens de elaboração do real visando a instruir e modificar nossas condições de percepção e nossas maneiras de nos apropriarmos do mundo.

Eu gostaria de me apoiar rapidamente sobre um último exemplo que já analisei antes mais detalhadamente ${ }^{6}$. Trata-se do trabalho de Guy Cassiers cujos espetáculos se impuseram a partir de 2006 na cena europeia. Na Bélgica, esse foi o ano de sua nomeação para a direção da Toneelhuis d'Anvers, um dos três teatros municipais

\footnotetext{
${ }^{6}$ Remeto aqui a um artigo assinado em parceria com Chloé Larmet, Guy Cassiers: les images entravées (Bident; Lamert, 2014, p. 42-48)
} 
em Flandres, onde ele desenvolve uma política de pluralidade de artes que pratica desde sua formação nas Belas Artes (Académie des Beaux-Arts d'Anvers). Com efeito, Cassiers começou sua carreira de encenador, ao longo dos anos 1980, organizando festas estudantis que assumiam as vezes de verdadeiras performances artísticas. O seu teatro visual, musical e plástico já se situava no cruzamento das artes da performance, em um espírito de criação coletiva que não o deixará mais. Assim, no Toneelhuis, Cassiers instala no centro da instituição um núcleo coletivo e artístico reunindo a dança, o cinema, o vídeo, a música e o teatro, tendo como artistas associados o performer Benjamin Verdonck; o coletivo Olympique Dramatique; o autor, dramaturgo, encenador e poeta Bart Meuleman, a autora e atriz Abke Haring, o coreográfo Sidi Larbi Cherkaoui. Por sua programação e sua produção, o Toneelhuis se torna deliberadamente um teatro atravessado. Quanto às criações nas quais Cassiers se responsabiliza pela encenação, elas assumem, em um grau raro, uma extrema atenção à composição literária, em particular à linguagem do romance (Lowry, Proust, Musil ...), e um incrível virtuosismo no manejo dos dispositivos visuais e sonoros. Se há claramente uma assinatura Cassiers, cada espetáculo modifica profundamente os modos de apresentação dessas alianças criativas. Entretanto, algumas constantes se verificam. As vozes dos atores são sonorizadas. Cassiers coloca câmeras em todos os lugares da caixa cênica, para difundir suas imagens (os rostos dos atores, detalhes da cenografia...) sobre grandes telas instaladas ao fundo ou sobre uma parte do palco. As projeções são manipuladas ao vivo pelos operadores, com os quais ocorre que os próprios atores, se beneficiando de um monitor de controle, possam dialogar, contribuindo assim duplamente com a construção da imagem. Essas imagens, portanto, não se deixam olhar passivamente. Elas se olham e nos olham. Cada um, de todos os lados, encenador, ator, técnico, espectador, as ativa e as entrava. Elas criam obstáculos entre elas e, no entanto, parecem adquirir uma liberdade nova. Elas tendem a desmaterializar corpos que, entretanto, ressuscitam e as manipulam. Elas sobrecarregam um texto cuja força sonora e vocal as devora. Cassiers procura fazer com que os espectadores trabalhem, que se tornem os criadores de suas próprias visões. Os olhares dos espectadores seguem um primeiro movimento de decomposição - apreender tal ou qual elemento como distinto, extraí-lo de seu contexto, detalhá-lo -, depois, um segundo de recomposição de uma intriga que será paralela à intriga principal da peça. Cassiers procura estimular a inventividade do público, trabalhando nota- 
damente os leitmotive, de forma a provocar a memória sensível dos espectadores e a permitir reaproximações e recortes que constroem em seus espíritos uma significação plural. As milhares de páginas de Proust, de Woolf, de Lowry se tornam algumas horas de espetáculo, por vezes, em torno de 10, como no Maratona Musil; isso, todavia, exige sempre uma seleção, uma montagem, um destaque, uma decomposição, uma recomposição. Cada elaboração textual encontra uma elaboração cenográfica e tecnológica. Este encontro, que atravessa o teatro, propõe a cada espectador uma nova partilha, uma nova concepção do lisível e do sensível. Não é indiferente que Cassier situe este trabalho politicamente: simultaneamente pela inscrição de certas criações em uma série como a que ele havia chamado Tríptico do poder, pela escolha de romances-mundos criadores de uma consciência europeia, e pela ressonância de seu empreendimento artístico (sua criação, sua direção do Toneelhuis) em uma cidade na qual nacionalistas extremistas flamengos (da Flandres) flertam regularmente com a metade do conjunto dos eleitores.

Deliberadamente escolhidos por sua diferença, e sem que essa escolha pressuponha, porém, qualquer esgotamento, essas três experiências teatrais contemporâneas conjugam dimensões tais (do social ao filosófico, do literário ao jurídico, do tecnológico ao político...) que demandam uma leitura antropológica. Não que se trate, ainda que isso seja sempre necessário, de apreender o fato teatral, ou seria preciso dizer, performativo, unicamente por meio daquilo que está em seu entorno, como um "fato social total". E, por outro lado, não é o caso de retomar um modo de discurso que não se afastou completamente de sua postura colonizadora e narcísica. Gostaria, com essa leitura, de me referir às Metafísicas canibais de Eduardo Viveiros de Castro7. Nesse trabalho, o antropólogo brasileiro realiza um gesto radical, simultaneamente antropológico e meta-antropológico, produzindo o que ele nomeia como uma "antropologia invertida", que se abre realmente e completamente às categorias dos povos que ela toma por objetos, chegando a considerar suas ideias como conceitos que elaboram um pensamento suscetível de ler os pensamentos dos outros e, dentre os quais, portanto, o nosso. O livro opera uma desconstrução do duplo dispositivo lévi-straussiano de 1962, O totemismo hoje (Le totémisme aujourd'huie) e O pensamento selvagem (La pensée

\footnotetext{
7 As citações desse livro que se seguirão foram extraídas da tradução francesa de Oiara Bonilla (VIVEIROS DE CASTRO, 2009, respectivamente, p. 53, 39 e 194).
} 
sauvage), a fim de detectar uma tendência ou antes um temor pós-estruturalista no próprio Lévi-Strauss. Ele opõe assim o multiculturalismo declarado da antropologia ocidental ao multinaturalismo canibal das concepções tupi. A oposição é simultaneamente de compreensão e de extensão. Entre os pares de contrários que ela recusa, um paradigma me parece mais decisivo que todos: aquele da representação e da perspectiva. O multiculturalismo não pode operar com um processo diferenciado de reconhecimento que não seja por via da representação, o que faz com que o outro permaneça integrado em um sistema. O multinaturalismo é um perspectivismo. Ele faz de cada animal (em particular de cada predador) uma pessoa e atribui a cada ato sacrificial ou xâmanico uma virtude transformadora para além de toda ficção. Assim, Viveiros de Castro pode afirmar: "uma perspectiva não é uma representação" e acrescentar: "uma perspectiva não é uma representação, porque as representações são propriedades do espírito, enquanto o ponto de vista está no corpo".

É este ponto de vista no corpo que os deslocamentos de BR-3, os dispositivos do grupo Berlin e as escritas literárias, visuais e sonoras de Cassiers suscitam. Eles não visam a produzir, junto aos espectadores, representações, porém, mais propriamente perspectivas: deslizamentos perceptivos, desligamentos conceituais, desfiliações, desnarcisações, desmultiplicações. Procedendo desse modo, eles reforçam a parte propriamente teatral do teatro, fundada sobre a troca. Eles multiplicam essas trocas de pontos de vista, entre cidades, entre vidas, entre margens, entre livros, entre corpos (mais precisamente: entre assassino e vítima, no Mathon Musil, entre homem e mulher no interior do mesmo corpo, em Orlando, para retomar espetáculos de Cassiers). Eles liberam o que Viveiros de Castro nomeia como "uma circulação infinita de perspectivas" - "troca de troca, metamorfose de metamorfose, ponto de vista sobre ponto de vista, quer dizer: devir". Eles não visam a dar nenhuma aula e colocam em ação, cada um de modo diferenciado, a política do "mestre ignorante" à qual se refere Jacques Rancière e que ele encontra em grau tão minoritário na criação espetacular. Eles promovem novos processos de subjetivação. E, se eles instauram um teatro em "campo expandido", é precisamente para o atravessar, sem descanso, por uma infinidade de saberes e de sujeitos de saber. 


\section{Referências}

AUDIO, Roberto, FERNANDES, Sílvia (org.). BR-3. São Paulo: Perspectiva/ EDUSP, 2006.

BIDENT, Christophe e LARMET, Chloé. Guy Cassiers: les images entravées. Théâtre Public, $\mathrm{n}^{\circ} 212$, avril-juin 2014, p. 42-48.

PINÇON, Guillaume. Anthropophagie du dehors: étude de théâtralités contemporaines au Brésil. Thèse inédite. Université de Picardie-Jules Verne, 2013. [Antropologia do fora: estudo de teatralidades contemporâneas no Brasil. Tese inédita defendida em co-tutela internacional. Universidade Federal do Estado do Rio de Janeiro - UNIRIO].

RANCIÈRE, Jacques. Le Spectateur émancipé. Paris: La Fabrique, 2008.

STANISLAVSKI, Constantin. Notes artistiques [1907-1913]. Trad. Macha Zonina et Jean-Pierre Thibaudat. [Belval]: Circé, 1997.

VIVEIROS DE CASTRO, Eduardo. Métaphysiques cannibales. Trad. Oiara Bonilla. Paris: Presses Universitaires de France, collection « Métaphysiques », 2009. 